\title{
Evaluation of the Mechanical Behavior of Mortars Obtained By Geopolymerization of Calcined Clay and Demolition Mortar
}

\author{
D.L. Mayta-Ponce', V.C. Bringas-Rodríguez ${ }^{1}$, J.F. Gamarra-Delgado1, M.L. Benavides-Salinas', \\ C.K. Palomino-Naupa ${ }^{1}$, G.P. Rodríguez-Guillén ${ }^{1}$ and F.A. Huamán-Mamani ${ }^{1}$ \\ ${ }^{1}$ Grupo de Investigación en Ciencia y Tecnología de Materiales, Departamento de Ciencias Naturales, Universidad \\ Católica San Pablo, Arequipa, Perú \\ Urb. Campiña Paisajista, Quinta Vivanco s/n, Arequipa 04001, Perú \\ dlmayta@ucsp.edu.pe; veronicawnh@gmail.com; frank.gamarra23@gmail.com; mirandabenavides7@gmail.com; \\ cpalominon@unsa.edu.pe; gprodriguez@ucsp.edu.pe; fhuaman@ucsp.edu.pe
}

\begin{abstract}
Geopolymeric mortars were prepared from a mixture of calcined clay powders (from demolition bricks), demolition mortar and a 12 molar alkaline hardening solution of sodium hydroxide. The geopolymeric mortars were compared physically, microstructurally and mechanically with their Portland cement counterparts. The results revealed similar densities between both types of mortars (geopolymeric and ordinary Portland cement). The microstructure was also similar in both mortars, two phases can be clearly identified, the continuous binder phase and the phase of individual fine sand particles dispersed within the continuous cement phase. Regarding the mechanical data, it could be verified that the mixture with $80 \mathrm{Vol} \%$ of fine sand, $10 \mathrm{Vol} . \%$ of calcined clay and $10 \mathrm{Vol} . \%$ of demolition mortar was the one that showed the best mechanical results, with an average mechanical resistance of $34.5 \mathrm{MPa}$. However, the highest average mechanical strength value for geopolymeric mortars is below the average mechanical strength value of ordinary Portland cement $\operatorname{mortar}(50 \mathrm{MPa})$.
\end{abstract}

Keywords: mechanical behavior, mortars, geopolymerization, calcined clay, demolition mortar, Portland cement

\section{Introduction}

Geopolymers are a class of inorganic synthetic materials obtained at room temperature by a chemical process called geopolymerization, which consists of the solubilisation of amorphous phases of aluminosilicates present in industrial solid waste, calcined clays, natural minerals, among others, by the action of a alkaline activator in aqueous solution [1,2]. Geopolymers have received extensive interest of the scientific community in recent years, mainly due to the variety of applications in which they can be used, this derived from their excellent fire resistance, low density, low cost, easy manufacturing, excellent chemical/thermal stability and eco-friendly synthesis $[3,4]$.

For some years these materials have been considered revolutionary for their potential use as an alternative material to ordinary Portland cement [5,6]. Several research papers have reported that geopolymeric concretes can reach up to $70 \%$ of maximum compressive strength within the first 4 hours of curing at an appropriate temperature [7], unlike Portland cement concretes, which require up to 28 days to reach maximum mechanical resistance. On the other hand, geopolymeric concrete shows very little shrinkage due to drying, it was noticed that after one year it presents between 5 to 7 times less shrinkage than Portland cement concrete [8,9]. On the other hand, several works have shown the negative influence of sulfates on Portland cement concrete, which drastically reduces its mechanical resistance to compression, this reduction is explained by the reaction of sulfates with the calcium present in Portland cement, which leads to the formation of gypsum and ettringite [10], which are phases that require a greater volume and therefore their formation generates internal stresses in the Portland cement concrete, which then lead to nucleation and propagation of cracks. On the other hand, geopolymeric concrete does not present similar problems because its properties depend on other types of reactions (in the absence of calcium) [11,12].

Geopolymeric concretes exhibit good mechanical response to high temperatures compared to their Portland cement concrete counterparts; in this regard, Kong et al. [12] studied the mechanical behavior of Portland cement and geopolymer pastes after being subjected to high temperatures, noticing that while at $800{ }^{\circ} \mathrm{C}$ the geopolymer paste improves its resistance to compression, Portland cement paste at $400{ }^{\circ} \mathrm{C}$ lost all its residual resistance, this loss of resistance of the Portland cement paste was attributed to the decomposition of $\mathrm{Ca}(\mathrm{OH})_{2}$ at approximately $400{ }^{\circ} \mathrm{C}$. One of the most important materials in the composition of conventional concretes is Portland cement, which is basically a mixture of gypsum and clinker, the latter is 
obtained by calcining limestone and clay at temperatures from $1350{ }^{\circ} \mathrm{C}$ to $1450{ }^{\circ} \mathrm{C}$. Obtaining the Clinker is accompanied by large $\mathrm{CO}_{2}$ emissions. In this regard, it has been determined that a cement kiln produces approximately 0.8 tons of $\mathrm{CO}_{2}$ for every ton of Portland cement [13].

\section{Materials and Methods}

\subsection{Sample Preparation}

Adequate amounts of binder and fine sand were ground in an alumina mortar and then sieved separately on an ASTM \# 140 sieve $(106 \mu \mathrm{m})$, then based on $20 \mathrm{~g}$. of powder mixes and with the matrices of mixes of table 1 were prepared. In the case of geopolymeric mortars (GM) samples, binding powders and $10 \mathrm{ml}$ of $\mathrm{Na}(\mathrm{OH})$ solution were mixed for 5 minutes, then the corresponding mass of fine sand (FS) was added and mixed for another 5 minutes, the GM paste obtained was compacted for 5 minutes at $60 \mathrm{MPa}$ in a $20 \mathrm{~mm}$ diameter hardened steel cylinder mold. In the case Portland cement mortars (M-PC) samples, the PC powder was mixed for 5 minutes with $10 \mathrm{ml}$ of drinking water, the following preparation steps were similar to those followed for GM samples preparation. The cylindrical specimens of GM and M-PC obtained were placed in hermetic bags for 7 days and then dried in an oven at $60^{\circ} \mathrm{C}$ for 24 hours.

Table 1. Matrix of mixtures for the preparation of geopolymeric (GM) and conventional mortars of

\begin{tabular}{l|c|ccc}
\hline \multirow{2}{*}{ sample } & $\begin{array}{c}\text { fine sand } \\
(\text { FS) } \\
\text { (Vol.\%) }\end{array}$ & $\begin{array}{c}\text { Portland cement (M-PC) } \\
\text { (Vol.\%) }\end{array}$ & $\begin{array}{c}\text { BINDER } \\
\text { (Vol.\%) }\end{array}$ & $\begin{array}{c}\text { Portland cement (PC) } \\
\text { (Vol.\%) }\end{array}$ \\
\hline M-20CCDDM & 80 & 20 & 0 & 0 \\
M-15CC5DM & 80 & 15 & 5 & 0 \\
M-10CC10DM & 80 & 10 & 10 & 0 \\
M-5CC15DM & 80 & 5 & 15 & 0 \\
M-0CC20DM & 80 & 0 & 20 & 0 \\
M-20PC & 80 & 0 & 0 & 20 \\
\hline
\end{tabular}

\subsection{Physical, Structural, Microstructural and Mechanical Characterization}

All prepared mortars were physically, microstructurally and mechanically characterized. The physical characterization consisted in the determination of the real density by the pycnometry technique, for this research a calibrated glass pycnometer and distilled water were used. The microstructural characterization was carried out on polished surfaces of the manufactured mortars. The preparation of the samples for microscopy began with a fine roughing of the surfaces using $\mathrm{SiC}$ abrasive paper of \# 600, \# 800 and \# 1200 grit, then surfaces were polished using diamond paste $(6,3$ and 1 micron) and lubricating liquid. The polished surfaces were cleaned with plenty of distilled water and were air dried, no grain development technique was used. Microstructural observations were made in an AMSCOPE brand light microscope (50X - 500X), model ME320B-PZ (USA).

The mechanical tests consisted of uniaxial compression tests at a constant compression speed of $0.05 \mathrm{~mm} / \mathrm{min}$, in an air atmosphere and were carried out in a universal testing machine, MICROTEST brand, model EM1 / 50 / FR, (Spain). Samples for compression tests consisted of $10 \times 5 \times 5 \mathrm{~mm}^{3}$ parallelepipeds and were obtained from cylindrical samples of set mortars. From the mechanical tests, force and displacement data were obtained, which were later converted into stress vs. deformation

\section{Results and Discussion}

\subsection{Physical and Microstructural Characterization}

The average real density for all the materials studied was $1.8 \mathrm{~g} / \mathrm{cm}^{3}$. Fig. 1 shows light microscopy micrographs of the six types of mortars studied, two well differentiated phases could be identified, on the one hand, a continuous phase in dark gray contrast that corresponds to the interconnected binder phase (Portland cement or mixture of calcined clay and demolition mortar) and, on the other hand, individual polygonal particles are seen dispersed within the continuous phase, which corresponds to the fine sand particles (light gray phase). 


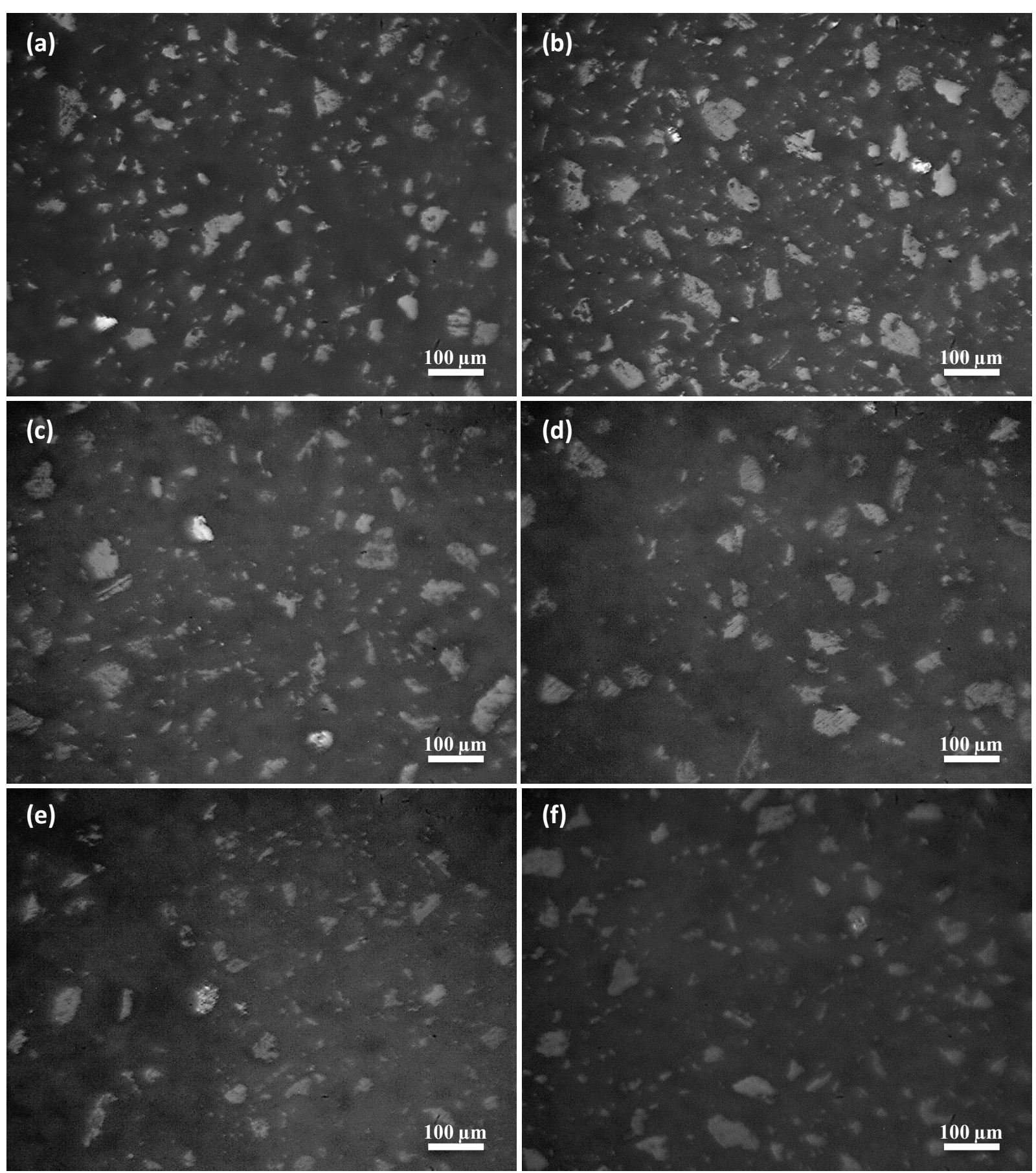

Fig. 1: Light microscopy micrographs of geopolymeric (a-e) and conventional Portland cement mortars (f)

\subsection{Mechanical Characterization}

Fig. 2 presents stress vs. strain for all the mortars studied, from these curves it could be noticed that the geopolymeric mortar M-10CC10DM in fig. 2 (c) with $80 \mathrm{Vol} \% \%$ of fine sand, $10 \mathrm{Vol} \% \%$ of calcined clay and $10 \mathrm{Vol} . \%$ of demolition mortar was the one that showed the best mechanical results, among all geopolymeric mortars, however, the data from maximum strengths for Portland cement mortars were higher than all the values found for geopolymeric mortars. 

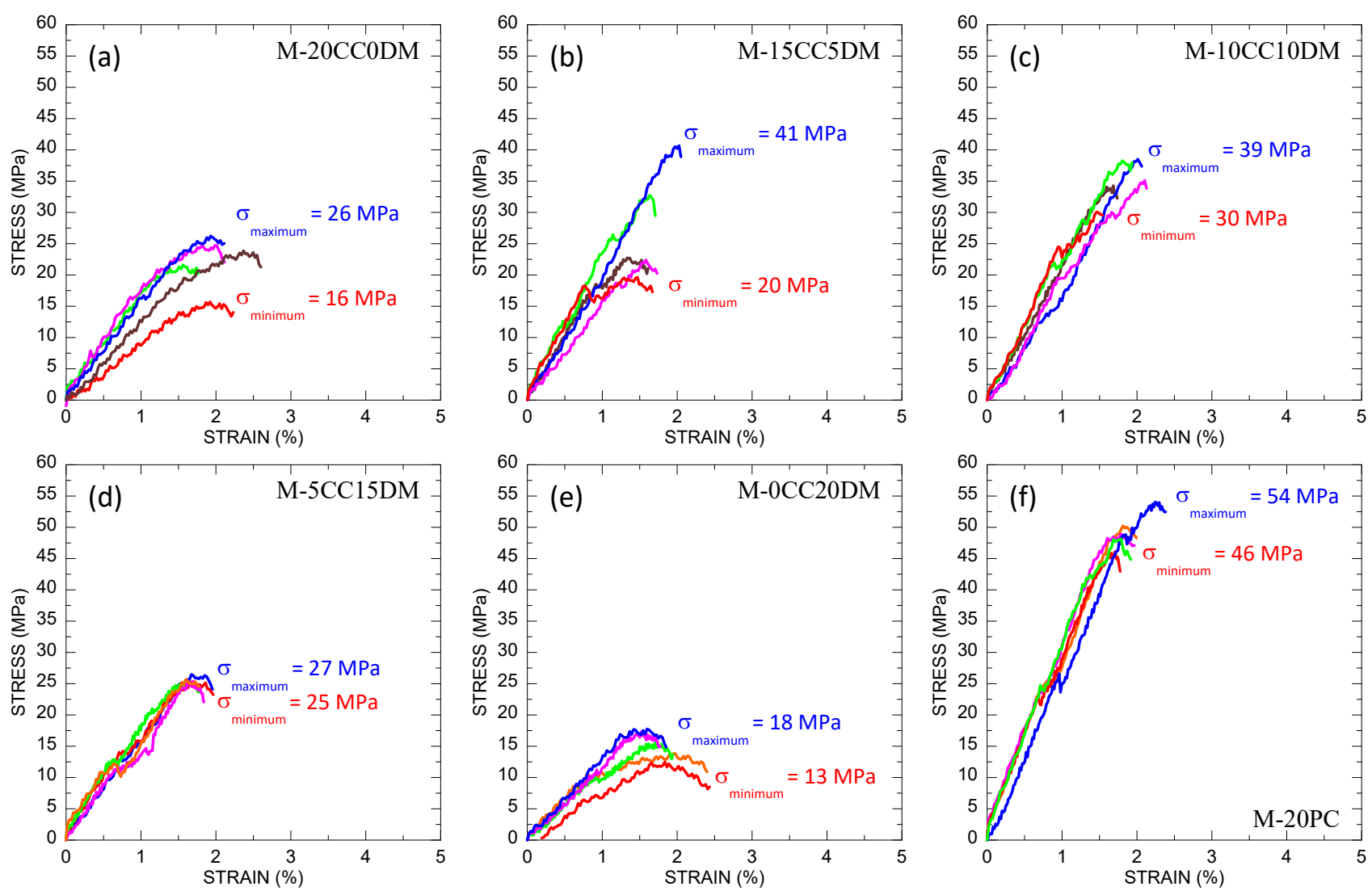

Fig.2: Stress vs. strain curves for the six types of mortars studied

\section{Conclusions}

Geopolymeric mortars derived from calcined clay powders and demolition mortar, and conventional Portland cement mortars were prepared and compared regarding their physical, microstructural and mechanical characteristics.

The real density of geopolymeric and conventional Portland cement mortars was similar and around $1.8 \mathrm{~g} / \mathrm{cm} 3$, on average.

The microstructure of geopolymeric and conventional Portland cement mortars was also similar, finding for both cases a continuous and interconnected binder phase of Portland cement or a mixture of calcined clay powders and geopolymerized demolition mortar and, on the other hand, polygonal particles were found individual dispersed within the continuous phase, which corresponds to the fine sand particles.

The geopolymeric mortar with $80 \mathrm{Vol} . \%$ of fine sand, $10 \mathrm{Vol} . \%$ of calcined clay and $10 \mathrm{Vol} . \%$ of demolition mortar was the one that showed the best mechanical results, among all the geopolymeric mortars studied.

The maximum mechanical resistance for Portland cement mortars were higher than all the values found for geopolymeric mortars.

\section{Acknowledgements}

This work was financed by CONCYTEC - FONDECYT within the framework of call E041-01 with contract $\mathrm{N}^{\circ}$ 36-2018-FONDECYT-BM-IADT-AV and was executed in the laboratories of the Universidad Católica San Pablo. 


\section{References}

[1] J. Davidovits, M. Davidovics, "Geopolymer: ultra-high temperature tooling material for the manufacture of advanced composites", Sampe 36 (2) (1991), pp. 1939-1949.

[2] Hamdy K. Shehab, Ahmed S. Eisa, Ahmed M. Wahba, "Mechanical properties of fly ash based geopolymer concrete with full and partial cement replacement", Construction and Building Materials, vol. 126, pp. 560-565, 2016.

[3] Bo Wei, Yimin Zhang, Shenxu Bao, "Preparation of geopolymers from vanadium tailings by mechanical activation", Construction and Building Materials, vol. 145, pp. 236-242, 2017.

[4] Jingkun Yuan, Peigang He, Peifeng Zhang, Dechang Jia, Delong Cai, Zhihua Yang, Xiaoming Duan, Shengjin Wang, $\mathrm{Yu}$ Zhou, "Novel geopolymer based composites reinforced with stainless steel mesh and chromium powder", Construction and Building Materials, vol. 150, pp. 89-94, 2017.

[5] Bo Wei, Yimin Zhang, Shenxu Bao, "Preparation of geopolymers from vanadium tailings by mechanical activation" Construction and Building Materials, vol. 145, pp. 236-242, 2017.

[6] F.N. Okoye, "Geopolymer binder: A veritable alternative to Portland cement", Materials Today: Proceedings, vol. 4, Issue 4, Part E, 2017, pp. 5599-5604.

[7] Davidovits J., "Properties of Geopolymer Cements", First International Conference on Alkaline Cements and Concretes, pp.131-149, 1994.

[8] Wallah SE, "Drying Shrinkage of Heated-Cured Fly Ash-Based Geopolymer Concrete", Modern Applied Science, 3(12), pp. 14-21, 2009.

[9] Ferraris CF, Clifton JR, Stutzman PE, Garboczi EJ, "Mechanisms of degradation of Portland cement-based systems by sulfate attack", Mechanisms of Chemical Degradation of Cement-Based systems; pp. 185-192, 1997.

[10] T. Bakharev, "Durability of geopolymer materials in sodium and magnesium sulfate solutions", Cement and Concrete Research, vol. 35, Issue 6, pp. 1233-1246, 2005.

[11] Wallah SE and Rangan BV, "Low-calcium fly ash-based geopolymer concrete long-term properties", Research Report GC2, Curtin University of Technology, 2006.

[12] Kong DLY and Sanjayan JG., "Effect of elevated temperature son geopolymer paste, mortar and concrete", Cement and Concrete Research, 40(2), pp. 334-339, 2010.

[13] Jeff Borger, Ramon L. Carrasquillo, David W. Fowler., "Use of recycled wash water and returned plastic concrete in the production of fresh concrete", Advanced Cement Based Materials, vol. 1, Issue 6, pp. 267-274, 1994. 